\title{
DESIGN AND CHARACTERIZATION OF OROSLIPPERY BUOYANT TABLETS FOR RANITIDINE HYDROCHLORIDE
}

\author{
NIDHAL K MARAIE*, ZEINA D SALMAN, NORA ZAWAR YOUSIF \\ Department of Pharmaceutics, College of Pharmacy, University of Mustansiriyah, Baghdad, Iraq. \\ Email: pharm.dr.nidhal.khazaal@unomustansiriyah.edu.iq \\ Received: 12 August 2017, Revised and Accepted: 20 August 2017
}

\begin{abstract}
Objective: The goal behind of performing this study was to come out with an oroslippery buoyant ranitidine hydrochloride tablet to ease the swallowing process. Hence, the drug is released controllably in the stomach regardless of the effect on gastric emptying time.

Materials and Methods: The core of the buoyant containing $150 \mathrm{mg}$ of the drug was compressed directly, and sodium bicarbonate was employed as an effervescent agent, besides, hydroxyl propyl methyl cellulose (HPMC) polymer was utilized in different grades in the formulation process. The prepared core was immersed in the coating dispersion, which was formulated using xanthan gum (slipping agent) and Kollicoat instant release (IR) (for film formation). According to the variables in the formulation process, floating properties varies along with the release profile of the drug; therefore, investigation of the effects of variables was conducted, including polymer type and concentration in the core part, and the effect of Kollicoat IR amount as well as the level of coating.
\end{abstract}

Results: According to this study, it was clearly obvious that T4 formulation, that consisted of HPMC K4M, after being dipped 2 times in dispersion of $0.3 \%$ xanthan gum and $14 \%$ Kollicoat IR, had provided an instant floating, moreover, the in vivo slipperiness was quite acceptable as well as the taste masking. Nevertheless, the percentage of drug release measured after $6 \mathrm{~h}$ was $90.15 \%$.

Conclusion: The resultant formulas is quite promising to take the lead as new approach to easy swallowing tablets without need of water especially for patients with swallowing problems as well as it is floating tablet that can retain the drug in gastric cavity to be continuously released to ensure its maximum absorption and may improve its bioavailability.

Keywords: Ranitidine hydrochloride, Oroslippery tablet, Gastro retentive, Buoyant, Kollicoat infrared, Xanthan gum.

(C) 2018 The Authors. Published by Innovare Academic Sciences Pvt Ltd. This is an open access article under the CC BY license (http://creativecommons. org/licenses/by/4. 0/) DOI: http://dx.doi.org/10.22159/ajpcr.2018.v11i1.21982

\section{INTRODUCTION}

Pharmaceutical industry started to persuade novel drug delivery system to optimize both safety and efficacy of the drug, through formulation the drug into a convenient dosage form. Oral dosage form has profound manifestation of inconveniency from swallowing point of view especially for pediatrics, elderly, disabled or bedridden and psychiatrists, resulting in patient noncompliance hence ineffective therapy, which falls into the need to develop various tablet dosage forms to avoid this problem. The drugs are administered via the oral route without the aid of chewing or prior dispersion/dissolution in water so a systemic effect can be produced $[1,2]$. So far, oroslippery tablets (OSTs), a new tablet dosage form, had been developed to avoid dysphagia as well as optimizing the traditional tablet dosage form, this dosage form relays on hydration of the tablet inside the oral cavity which offers slipperiness easily of an intact tablet without water aid, moreover, it provide taste masking through the same concept [3].

Ranitidine hydrochloride (RHCl), an H2-receptor blocker that reduces gastric acid secretion (stimulated by histamine, gastrin, and cholinomimetic agents), as raw material it has a bitter taste and sulfur-like odor. In general, it is prescribed in the management of duodenal ulcer, gastric ulcer, and gastroesophageal reflux disease as well as erosive esophagitis. The latter condition requires about $150 \mathrm{mg}$ of ranitidine 4 times a day. While administering $150 \mathrm{mg}$ of the drug, conventional dose, the gastric acid secretion is inhibited up to no more than $5 \mathrm{~h}$, while administering $300 \mathrm{mg}$ can cause plasma fluctuations; accordingly, a sustained release dosage form is more preferred [4]. As ranitidine has a short biological half-life, about 2.5-3 h, had urged the development of a sustain release formula. Ranitidine is solely absorbed from the initial part of the small intestine with a resultant absolute bioavailability of $50 \%$ of the administered dose [5].

New formulations have been developed to provide gastro retentive drug delivery, such as floating drug delivery, those are of low-density system that possesses an adequate buoyancy to float over the gastric contents to remain for prolonged time in the stomach regardless to the gastric emptying rate. The floating system provides the required condition to retain the drug within the cavity, therefore improving the sustained delivery of drugs given orally, that have a particular absorption window at a particular location on the gastrointestinal tract (GIT).

Those systems aid in continuously releasing of the drug prior it reaches its absorption window, so an optimal bioavailability can be achieved, moreover, the local delivery increase the bioavailability at the receptor site in the stomach, therefore, increase the efficacy of the drug by reducing the acid secretion [6]

The aim of this study was to develop a novel strategy by application of a slippery coat over intragastric core buoyant tablet of RHCl for easily swallowing process, good taste masking, high efficacy and controlled release that may lower dose, and improve bioavailability so to achieve a better compliance and can be used as alternative for the conventional non-coated tablet of the same drug.

\section{MATERIALS AND METHODS}

Materials

RHCl was provided by (Bio-technology Co., Ltd.), HPMC (K4M, K15M, K100M) (Provizerpharma, India), Kolicort IR, (Sigma Chemical Co., 
(Aldrich), USA), xanthan gum, Avecil, $\mathrm{NaHCO}_{3}$, citric acid, mannitol, and magnesium stearate (Samara Drug Industry, Iraq). Peppermint oil and talc (Himedia, India). All other chemicals, solutions and reagents used were of analytical grade.

\section{Methods}

Preparation of the OSTS

Preparation of buoyant core tablet

The composition of different formulations of RHCl buoyant core tablets is shown in (Table 1). The tablets were prepared by direct compression method. $\mathrm{RHCl}$, polymer (HPMC of different grades), gas generating agent (sodium bicarbonate), and diluent (microcrystalline cellulose) were weighed separately and passed through sieve no. 0.36 . The active ingredient and excipients except the talc and magnesium stearate were mixed together for $15 \mathrm{~min}$ in a plastic container, the remaining ingredients were added to the previous mixture and mixed for extra $2 \mathrm{~min}$. The final blend was compressed directly into tablets of average weight $400 \mathrm{mg}$ using a single punch tablet of a die size $11 \mathrm{~mm}$ and compression force 8 [7].

Preparation of the aqueous slippery coating

The aqueous coating dispersion prepared in three steps:

Step 1: Preparation of the xanthan gum

The slipperiness inducing agent, xanthan gum (xan) [8], was added to a $40^{\circ} \mathrm{C}$ preheated distilled water while being mixed using magnetic stirrer at $600 \mathrm{rpm}$ speed for $5 \mathrm{~min}$.

Step 2: Preparation of the Kollicoat IR solution

Kollicoat IR was added gradually to mannitol containing aqueous solution with continuous stirring. Mannitol was used as a sweetening and flavor agent [9]. Stirring was conducted using magnetic stirrer at $100 \mathrm{rpm}$ for $15 \mathrm{~min}$ at room temperature until a clear solution was formed.

Step 3: Preparation of the coating mixture

Aqueous dispersion of xanthan gum (Step 1) was added to the polymeric solution (Step 2) and mixing together using magnetic stirrer at $400 \mathrm{rpm}$ for $5 \mathrm{~min}$ at room temperature, then peppermint oil and talc (anti-adherent and distributing agent) were added with continuous stirring at $400 \mathrm{rpm}$ for extra $5 \mathrm{~min}$ at room temperature. Peppermint oil has a role of flavoring and cooling agent [10]; which further enhances patient compliance, also enhances the swallowing process through salivation process [11]. All constituents of the coating dispersion are shown in Table 2.

\section{Coating $\mathrm{RHCl}$ core tablets}

Buoyant OSTs of $\mathrm{RHCl}$ were prepared by dipping the core buoyant tablet (F6 which has optimum release rate and acceptable lag time as compared to other buoyant formulas) in each of the slippery coating solutions (S1, S2, and S3) using a suitable forceps, thereafter drying at $60^{\circ} \mathrm{C}$ by applying a hot air dryer for about $5 \mathrm{~min}$ (this procedure applied again to the dried single coated OSTs when double OSTs coating was prepared), Different OSTs prepared by immersing the core in different coating dispersion types and made different coating layers to study the effect of types and number of the coating layer on the release profile of the drug, floating lag time (FLT) and in vivo slipperiness, and the taste masking effect of the OSTs. The composition of the RHCl OSTs is shown in Table 3.

\section{Evaluation of the compressed tablets (before and after coating) Physical properties}

Prepared tablets were assessed for weight variation, tablet thickness and hardness, uniformity of dosage units, and friability.

The weight variation test was conducted by weighing 20 random tablets individually, calculating the average weight thereby comparing the individual weights to the average.

The hardness of each batch of tablets was measured in terms of $\mathrm{kg} / \mathrm{cm}^{2}$, where five tablets from each formula were tested through Monsanto hardness tester, and then the average reading \pm standard deviation (SD) was documented [12].

On the other hand, the friability test was conducted by placing 20 preweighed tablets in the friabilator; the latter was operated at $25 \mathrm{rpm}$ for 4 min; the dust was brushed off the tablets and reweighed. Tablets to be acceptable should lose a maximum of no more than $1 \%$ of their weight. Nevertheless, the thickness of each 10 tablets was measured with the Vernier Caliper $[13,14]$

\section{Determination of percent drug content (content uniformity)}

The content uniformity test of the tablets was done by weighing and powdering ten randomly sampled tablets from each formulation, and individually estimated for $\mathrm{RHCl}$ content after solubility in sufficient volume of $0.1 \mathrm{~N} \mathrm{HCl}$, via detection through UV-VIS spectrophotometer at $314 \mathrm{~nm}$ [15].

\section{In vitro buoyancy study ([FLT] and total floating time [TFT])}

The FLT can be defined as the time required by the tablet to be emerged on the surface of the dissolution medium, and the time the tablet constantly float on the medium surface is known as TFT as evaluated in a dissolution vessel filled with $900 \mathrm{ml}$ of $0.1 \mathrm{~N} \mathrm{HCl}(\mathrm{pH} 1.2)$ previously set at $37 \pm 0.50^{\circ} \mathrm{C}$ at $75 \mathrm{rpm}$, for both core and coated tablets [16].

\section{In vitro release study}

The in vitro release rates of ranitidine from slippery buoyant tablets formulas ( $\mathrm{F} 4-\mathrm{T} 6)(\mathrm{n}=3)$ were estimated via dissolution apparatus II (paddle method) [8]. The dissolution test was done using $900 \mathrm{ml}$ of $0.1 \mathrm{~N} \mathrm{HCl}$, at $37 \pm 0.50^{\circ} \mathrm{C}$ at $75 \mathrm{rpm}$. A sample ( $5 \mathrm{ml}$ ) of the solution was withdrawn from the dissolution apparatus at determined time intervals $(15,30,60,120,180,240,300$, and $360 \mathrm{~min})$ with the replacement of the sample with $5 \mathrm{ml}$ fresh dissolution medium. The samples were filtered through a $0.45-\mu$ membrane filter. Absorbance of these solutions was measured at $314 \mathrm{~nm}$ using a UV/Vis- spectrophotometer. Thereafter cumulative percentage, drug release was calculated by pre-determined equation obtained from a calibration curve $[17,18]$.

Table 1: The composition of ranitidine buoyant core tablets

\begin{tabular}{|c|c|c|c|c|c|c|c|c|}
\hline Formula code mg & F1 & F2 & F3 & F4 & F5 & F6 & F7 & F8 \\
\hline $\mathrm{RHCl}$ & 150 & 150 & 150 & 150 & 150 & 150 & 150 & 150 \\
\hline HPMC K4M & 160 & 160 & 160 & & & 80 & 100 & 120 \\
\hline HPMC 15M & & & & & 80 & & & \\
\hline HPMC 100M & & & & 80 & & & & \\
\hline Avecil & 64 & 44 & 24 & 84 & 84 & 84 & 64 & 44 \\
\hline $\mathrm{Na} \mathrm{HCO}_{3}$ & 20 & 40 & 60 & 80 & 80 & 80 & 80 & 80 \\
\hline Talc & 4 & 4 & 4 & 2 & 2 & 2 & 2 & 2 \\
\hline
\end{tabular}

RHCl: Ranitidine hydrochloride, HPMC: Hydroxyl propyl methyl cellulose 
Table 2: Composition of the coating dispersion $(\% \mathrm{w} / \mathrm{w})$

\begin{tabular}{llll}
\hline Ingredients & S1 (\%) & S2 (\%) & S3 (\%) \\
\hline Kollicoat IR & 9 & 14 & 19 \\
Xanthan gum & 0.3 & 0.3 & 0.3 \\
Mannitol & 2.5 & 2.5 & 2.5 \\
Talc & 2 & 2 & 2 \\
Peppermint oil & 0.5 & 0.5 & 0.5 \\
D.W & Up to 100 & Up to 100 & Up 100 \\
\hline
\end{tabular}

Table 3: Composition of ranitidine slippery coated buoyant tablet

\begin{tabular}{ll}
\hline Formula code & Composition \\
\hline T1 & F6 (S1) \\
T2 & F6 (S1)*2 \\
T3 & F6 (S2) \\
T4 & F6 (S2) $)^{* 2}$ \\
T5 & F6 (S3) \\
T6 & F6 (S3) $)^{* 2}$ \\
\hline 2
\end{tabular}

${ }^{* 2}$ double layer coating

Variables studied on the prepared formulas

Effect of effervescent agent on in vitro buoyancy properties

Formulas F1, F2, and F3 which contain $20 \mathrm{mg}, 40 \mathrm{mg}$, and $60 \mathrm{mg}$ of sodium bicarbonate, respectively, were utilized to study the influence of the amount of effervescent agent on floating properties of core tablets.

\section{Effect of different polymer grade}

Formulas (F4, F5, and F6) were utilized to study the effect of different polymer grades (HPMC K100M), HPMC K15M, HPM CK4M, respectively, on the floating properties and Drug release of core tablets.

\section{Effect of polymer amount}

Formulas (F6, F7, and F8) were prepared to study the influence of polymer amount on the floating properties and drug release of $\mathrm{RHCl}$ Core tablet in which formulas F6, F7, and F8 contain HPMC K4M $80 \mathrm{mg}$, $100 \mathrm{mg}$, and $120 \mathrm{mg}$, respectively.

\section{Effect of Kollicoat IR concentration in the coat of OSTS}

Formulas T1, T3, and T5 were planned to design to study the effect of changing Kollicoat IR concentration 9\%, 14\%, and19\%, respectively, on floating properties and release.

\section{Effect of coating level on floating property and release}

Formulas T1, T2, T3, T4, T5, and T6 were examined to demonstrate the effect of coating level on the floating property and release by dipping (single layer coating and double layer coating) on floating property and drug release.

\section{In vivo evaluation of slipperiness and taste masking effect}

All the in vivo evaluations tests were approved by the Ethics Committee of the College of Pharmacy, University of Mustansiriyah.

The evaluation of in vivo slipperiness was applied to the core tablet (F6) and OSTs formulas T1-T6, five healthy humans had volunteered to perform the test after gaining their full consent, the seconds required for the tablets to become slippery and swallowed whole without the aid of water was recorded and considered as an indicator for slipperiness degree.

To assure that the prepared OSTs remained intact with adequate taste masking during their residence in the oral cavity, the taste masking effect was performed using the rolling method [19] on the selected OSTs formulas T1-T6 and F6 (core tablet) on five healthy human volunteers whom got detailed briefing on the purpose of this test. The volunteers were told to roll the tablet gently in their oral cavity without chewing or biting; whenever a slight taste of bitterness can be detected the volunteered were informed to spit the tablet out along with the saliva and to rinse their mouth immediately. The time required for bitterness sensation was recorded and considered as an indicator for taste masking property for the prepared $\mathrm{RHCl}$ OSTs [3].

\section{Statistical analysis}

The results of the experiments were given as a mean values $\pm S D$ and were analyzed according to one-way analysis of variance (ANOVA) at which results considered significant when $(p<0.05)$ and non-significant when $(\mathrm{p}>0.05)$.

\section{RESULTS AND DISCUSSION}

\section{Evaluations of the prepared core and coated buoyant OSTs}

The prepared core tablet formulas (F1-F8) were evaluated for their physical properties, including hardness, friability, weight variation, drug content, and thickness, the results in Table 4 showed a nonsignificant difference $(p>0.05)$ between the prepared core tablets in their physical properties, with high tablet hardness $\left(5.7 \pm 0.73 \mathrm{~kg} / \mathrm{cm}^{2}\right)$ and lower friability value $(0.34 \%)$. Furthermore, physical properties for the prepared RHCl buoyant OSTs are illustrated in Table 5. They showed non-significant differences $(\mathrm{p}>0.05)$ in the hardness between the prepared in additions, non-significant differences were observed between the core and coated tablet hardness, indicating that the slippery coating had no significant influence $(p>0.05)$ on the core tablet hardness. All the prepared OSTs had an acceptable, non-significant difference $(p>0.05)$ in friability with a slight enhancement for coated tablets which resulted from higher coating thickness in double T2, T4, and $\mathrm{T} 6$ comparing to monolayer coating in $\mathrm{T} 1, \mathrm{~T} 3$, and $\mathrm{T} 5$ consequently.

Preliminary trail (F1-F3) was prepared to study the effect of amount of effervescent agent on floating property, the results of floating properties were shown in Table 6, as the amount of $\mathrm{NaHCO}_{3}$ increased, the FLT was decreased noticeably, this manner can be attributed to the fact that as the concentration of $\mathrm{NaHCO}_{3}$ increases the result of effervescence amount increases as well, which lead to formation of pores, which lead to rapid hydration of the HPMC K4M polymer matrix, therefore, reducing tablet floating time. Although all prepared formulas showed a TFT more than $24 \mathrm{~h}$, these three preliminary formulas were excluded from further studies, as they required a long time to float on the surface of the medium. HPMC in large concentration $(160 \mathrm{mg}) 40$ $\%$ of total tablet weight acts as a gelling and matrix forming agent, it has the ability to form strong mesh-like structure after contact with the dissolution media and thus slows down the release of $\mathrm{CO}_{2}$ (which had formed by reaction of $\mathrm{NaHCO}_{3}$ with dissolution medium) leading to increase in FLT [20].

The effect of polymer grade on FLT was studied in which F4, F5, and F6 contain HPMC K100M, HPMC K15M, and HPMC K4M, respectively, as the viscosity of the polymer increased, the FLT increased significantly $(p<0.05)$ this can be attributed to increase tablet integrity and formation of a stronger gel layer with increasing the polymer viscosity, thus more time is required to hydrate the tablet [21].

Fig. 1 shows the effect of polymer grade on drug release in which as the grade of the polymer changed (K100M in comparison with $\mathrm{K} 15 \mathrm{M}$ and $\mathrm{K} 4 \mathrm{M}$ ), the rate of drug release was decreased significantly $(\mathrm{p}<0.05)$. This behavior may be elucidated by the relation between the polymer viscosity and the disentanglement concentration (the critical concentration of the polymer below which the polymer chains separate and detach from a qualified matrix). The higher polymer viscosity makes greater chain entanglement, so it becomes harder for longer chains to dissolve. This lead to the formation of thicker gel and the ability to hold the liberated gas for a longer time, and not allow the fast diffusion of the drug from the tablet matrix $[22,23]$. 


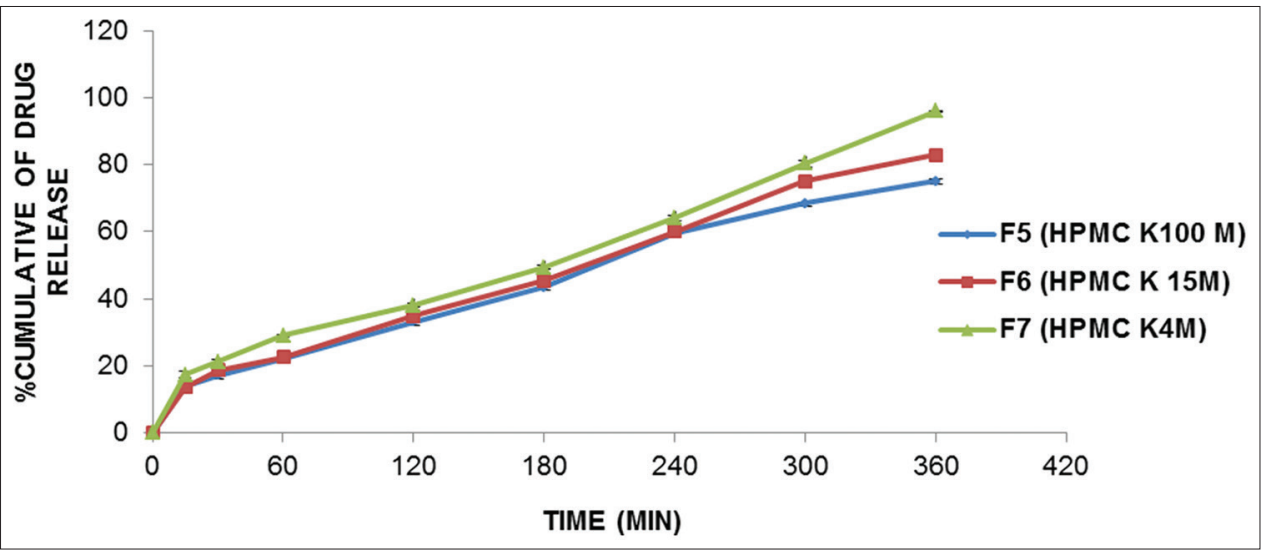

Fig. 1: Effect of HPMC grade on in vitro drug release of buoyant core tablet for ranitidine $\mathrm{HCl}$ in $0.1 \mathrm{~N} \mathrm{HCl}$ solution at $37 \pm 0.5^{\circ} \mathrm{C},(\mathrm{n}=3$ ) (mean \pm standard deviation)

Table 4: Physical properties of the prepared buoyant core tablets

\begin{tabular}{|c|c|c|c|c|c|}
\hline Formulas & Hardness $\left(\mathrm{kg} / \mathrm{cm}^{2}\right)$ & Weight variation (mg) & Thickness (mm) & Friability (\%) & Drug content $(\%)$ \\
\hline F1 & $5 \pm 0.56$ & $385.2 \pm 0.83$ & $4.1 \pm 0.38$ & $0.35 \pm 0.03$ & $94.5 \pm 0.09$ \\
\hline $\mathrm{F} 2$ & $5 \pm 0.43$ & $376.1 \pm 0.77$ & $4.3 \pm 0.28$ & $0.34 \pm 0.63$ & $95 \pm 0.05$ \\
\hline F3 & $5 \pm 0.33$ & $388.9 \pm 0.68$ & $4.3 \pm 0.08$ & $0.36 \pm 0.6$ & $93.5 \pm 0.03$ \\
\hline F4 & $5 \pm 0.06$ & $389 \pm 0.44$ & $4.8 \pm 0.67$ & $0.75 \pm 0.45$ & $97.6 \pm 0.03$ \\
\hline F5 & $4.9 \pm 0.03$ & $395 \pm 0.54$ & $4.6 \pm 0.08$ & $0.62 \pm 0.5$ & $98.3 \pm 0.33$ \\
\hline F6 & $4.9 \pm 0.27$ & $398 \pm 0.30$ & $4.2 \pm 0.83$ & $0.68 \pm 0.56$ & $99.6 \pm 0.1$ \\
\hline F7 & $5.5 \pm 0.8$ & $396 \pm 0.40$ & $4.3 \pm 0.33$ & $0.38 \pm 0.63$ & $94.6 \pm 0.63$ \\
\hline
\end{tabular}

Physical properties data represented by mean \pm SD ( $n=3)$. SD: Standard deviation

Table 5: Physical properties of the prepared OSTs

\begin{tabular}{|c|c|c|c|c|c|}
\hline Formulas & Hardness $\left(\mathrm{kg} / \mathrm{cm}^{2}\right)$ & Weight variation (mg) & Thickness (mm) & Friability (\%) & Drug content (\%) \\
\hline $\mathrm{T} 1$ & $4.9 \pm 0.02$ & $425.4 \pm 0.50$ & $4.30 \pm 0.03$ & $0.36 \pm 0.03$ & $98.4 \pm 0.09$ \\
\hline $\mathrm{T} 2$ & $4.8 \pm 0.2$ & $443.2 \pm 0.41$ & $4.41 \pm 0.53$ & $0.28 \pm 0.02$ & $97.6 \pm 0.02$ \\
\hline T3 & $4.8 \pm 0.05$ & $426.4 \pm 0.32$ & $4.33 \pm 0.05$ & $0.33 \pm 0.02$ & $95 \pm 0.2$ \\
\hline $\mathrm{T} 4$ & $4.9 \pm 0.03$ & $444.1 \pm 0.01$ & $4.46 \pm 0.33$ & $0.28 \pm 0.03$ & $99.5 \pm 0.089$ \\
\hline T5 & $4.7 \pm 0.31$ & $428.1 \pm 0.42$ & $4.36 \pm 0.8$ & $0.27 \pm 0.01$ & $99.1 \pm 0.05$ \\
\hline T6 & $4.8 \pm 0.23$ & $446.2 \pm 0.54$ & $4.48 \pm 0.11$ & $0.23 \pm 0.03$ & $96.4 \pm 0.55$ \\
\hline
\end{tabular}

Physical properties data represented by mean \pm SD $(n=3)$. SD: Standard deviation, OSTs: Oroslippery tablets

Table 6: FLT and TFT for prepared RHCl tablet

\begin{tabular}{lll}
\hline Formula code & FLT in seconds & TFT in hours \\
\hline F1 & $420 \pm 0.05$ & $>24$ \\
F2 & $333 \pm 0.5$ & $>24$ \\
F3 & $254.4 \pm 0.3$ & $>24$ \\
F4 & $43 \pm 0.23$ & $>24$ \\
F5 & $39 \pm 0.1$ & $>24$ \\
F6 & $26 \pm 0.02$ & $>24$ \\
F7 & $20 \pm 0.09$ & $>24$ \\
F8 & $18 \pm 0.02$ & $>24$ \\
T1 & $77.4 \pm 0.33$ & $>24$ \\
T2 & Instant floating & $>24$ \\
T3 & Instant floating & $>24$ \\
T4 & Instant floating & $>24$ \\
T5 & $110 \pm 0.07$ & $>24$ \\
T6 & Instant floating & $>24$ \\
\hline
\end{tabular}

The results of FLT and TFT for prepared RHCl tablets (F1-F6) for core tablets and (T1-T6) for oroslippery tablets represented by mean \pm standard deviation $(n=3)$. FLT: Floating lag time, TFT: Total floating time, RHCl: Ranitidine hydrochloride

The effect of polymer amount on FLT was studies in formulas F6, F7, and F8 which contain 80,100 and $120 \mathrm{mg}$, respectively, of HPMC K4M, as the amount of polymer increased there was a decrease in FLT this is may be due to the fact that increasing the amount of polymers caused rapid formation as well as entrapment of $\mathrm{CO}_{2}$ gas into the hydrophilic polymeric gel which eventually resulted in reduction of FLT [24].

The effect of polymer amount on drug release is shown in Fig. 2, in which as the amount of polymer in the formula increased, the rate of drug release decreased significantly $(p<0.05)$, This is due to the fact that higher polymer amount will form a stronger viscous gel layer that decrease the rate of water diffusion into the floating tablet matrix, which cause a decrease in drug release [25].

Formulas T1, T3, and T5 were planned to design to study the effect of different Kollicoat IR concentration in the coating layer $(9 \%, 14 \%$, and 19\%), respectively, on FLT and drug release. These formulas showed an increase in FLT except T3 (Table 6) which showed an instant floating this is may be related to the hydrophilicity and permeability of polymeric film for dissolution medium that results in rapid initiation of $\mathrm{CO}_{2}$ gas accompanied with matrix swelling forming a gel layer with which air is entrapped around the tablet core after contact with gastric fluid, after the outer gel layer is eroded, the swelling boundary is moving toward the dry core, maintaining hydration and buoyancy of the system. 
There was a non-significant decrease $(\mathrm{p}>0.05)$ in drug release as the concentration of coating Film polymer increased for T1 and T3 as seen in Fig. 3 while for higher concentration 19\% (T5) there was a significant decrease $(\mathrm{p}<0.05)$ in drug release since Kollicoat IR is hydrophilic film former polymer and this will lead to increase the rate and extent of water uptake by water-loving core polymer (HPMC) thus leads to formation of swollen gel matrix that leads to a retardation in drug release [26].

Doubling the coating layer as in formulas $\mathrm{T} 2$, $\mathrm{T} 4$, and $\mathrm{T} 6$ resulted in instant floating this is may be related to the high permeability of Kollicoat IR. From Fig. 4, it was noticed that there is non-significant decrease $(P>0.05)$ in drug release when comparing the single layer coated formulas T1, T3 with their double coated counterparts T2 and $\mathrm{T} 4$, respectively, while T6 showed a significant decrease $(P<0.05)$ in drug release in comparison to $\mathrm{T} 5$ this is may be related to coating thickness as the coating layer was doubled the thickness of diffusion pathway for the solvent to pass resulting in slower drug release $[27,28]$. As showed in Fig. 5.

In vivo slipperiness and taste masking effect of the prepared OSTs Concerning the results of in vivo slipperiness for (core tablet F6) and T1-T6 (coated tablet), Fig. 6 showed that the coated tablet had

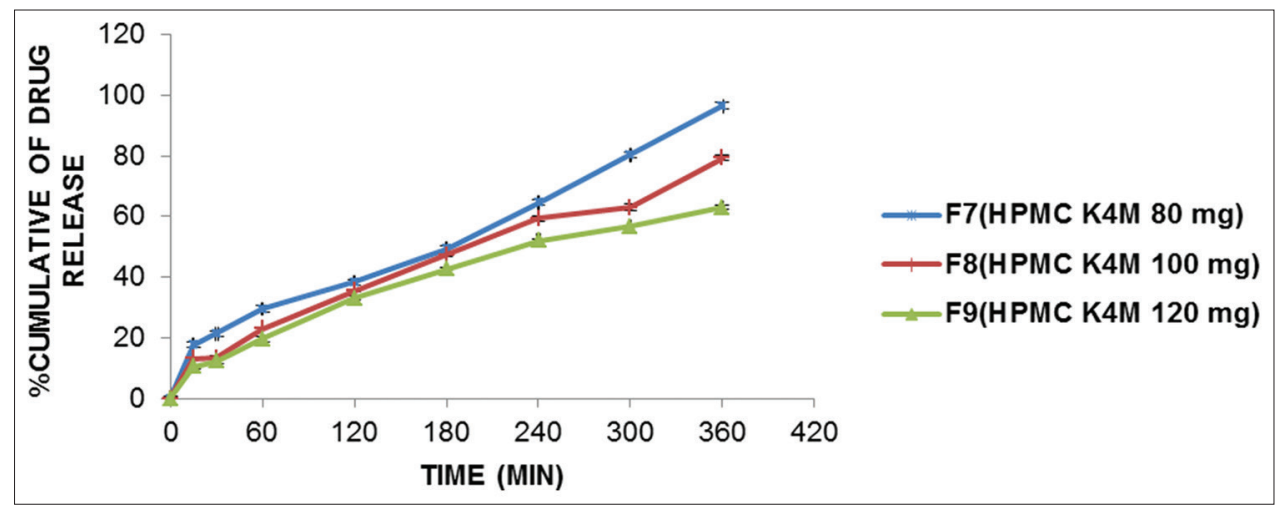

Fig. 2: Effect of HPMC K4M polymer amount on in vitro drug release of buoyant core tablet for ranitidine $\mathrm{HCl}$ in $0.1 \mathrm{~N} \mathrm{HCl}$ solution at $37 \pm 0.5^{\circ} \mathrm{C},(\mathrm{n}=3)$ (mean \pm standard deviation)

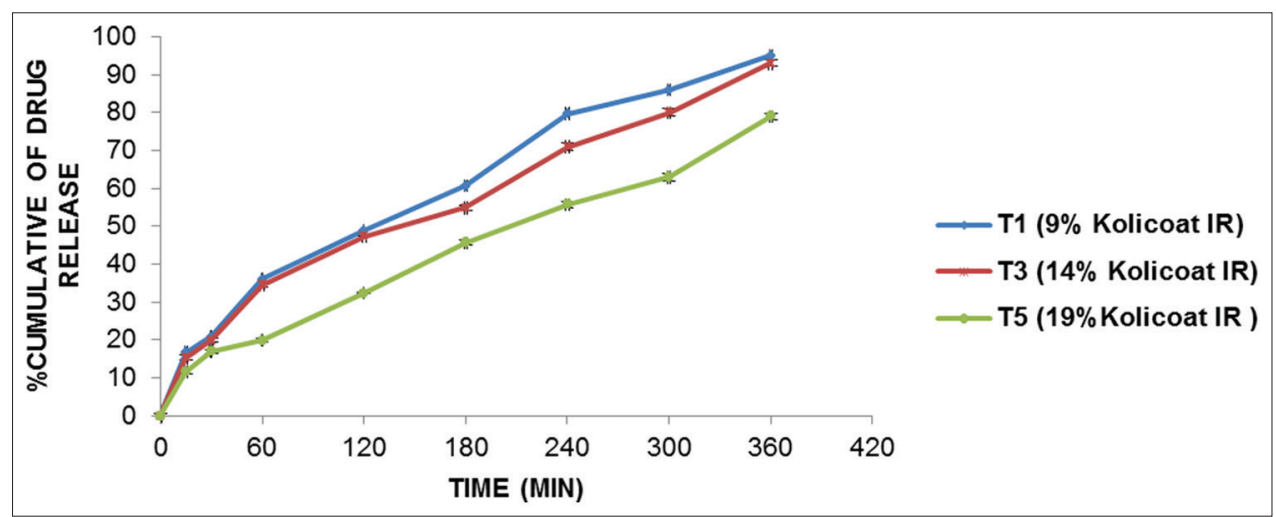

Fig. 3: Effect of increasing Kollicoat IR concentration of coat dispersion on in vitro drug release of ranitidine oroslippery tablet in $0.1 \mathrm{~N}$ $\mathrm{HCl}$ solution at $37 \pm 0.5^{\circ} \mathrm{C},(\mathrm{n}=3)($ mean \pm standard deviation)

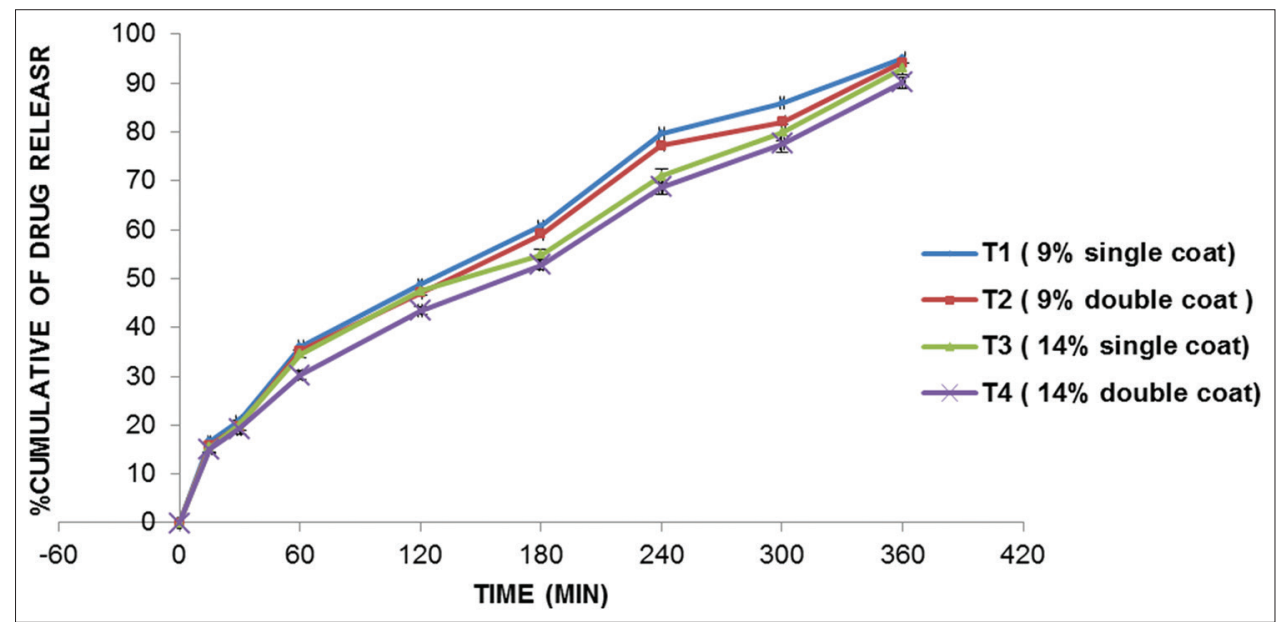

Fig. 4: Effect of coating layer level of (Kollicoat IR $9 \%$ and 14\%) on in vitro drug release of ranitidine oroslippery tablet in $0.1 \mathrm{~N} \mathrm{HCl}$ solutions at $37 \pm 0.5^{\circ} \mathrm{C},(\mathrm{n}=3)$ (mean \pm standard deviation) 


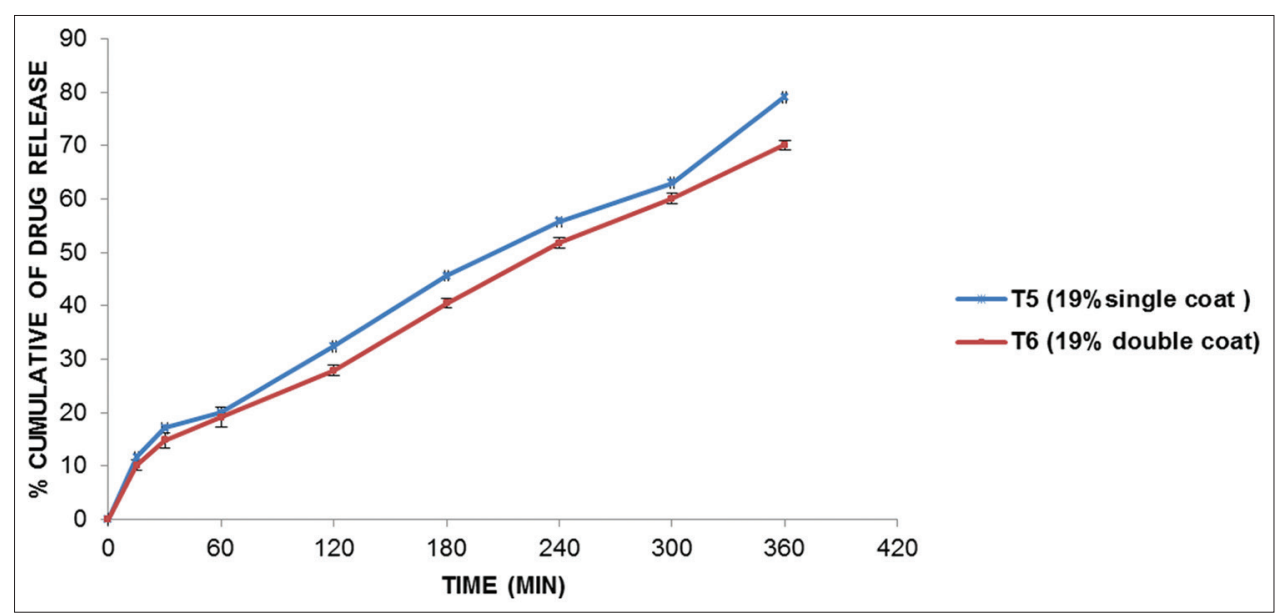

Fig. 5: Effect of coating layer level of (Kollicoat IR 19\%) on in vitro drug release of ranitidine oroslippery tablet in $0.1 \mathrm{~N} \mathrm{HCl} \mathrm{solutions} \mathrm{at}$ $37 \pm 0.5^{\circ} \mathrm{C},(n=3)$ (mean \pm standard deviation)

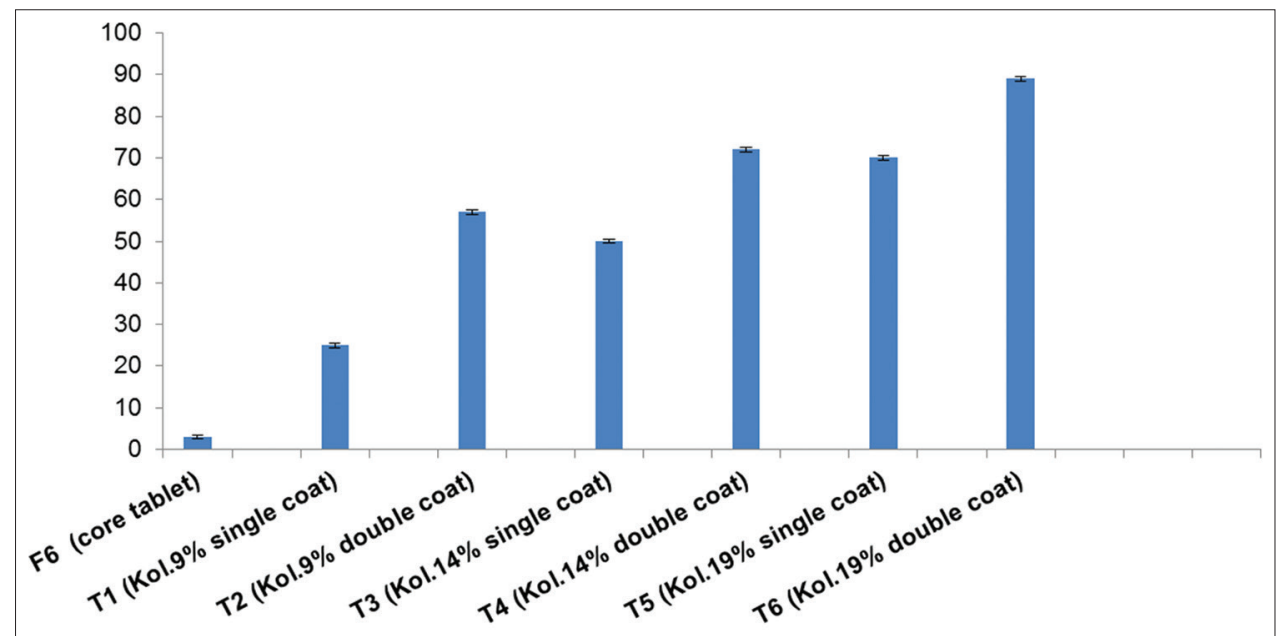

Fig. 6: The result of in vivo slipperiness test for ranitidine hydrochloride buoyant core and oroslippery tablets represented by mean \pm standard deviation $(n=3)$, F6 shown no slipperiness

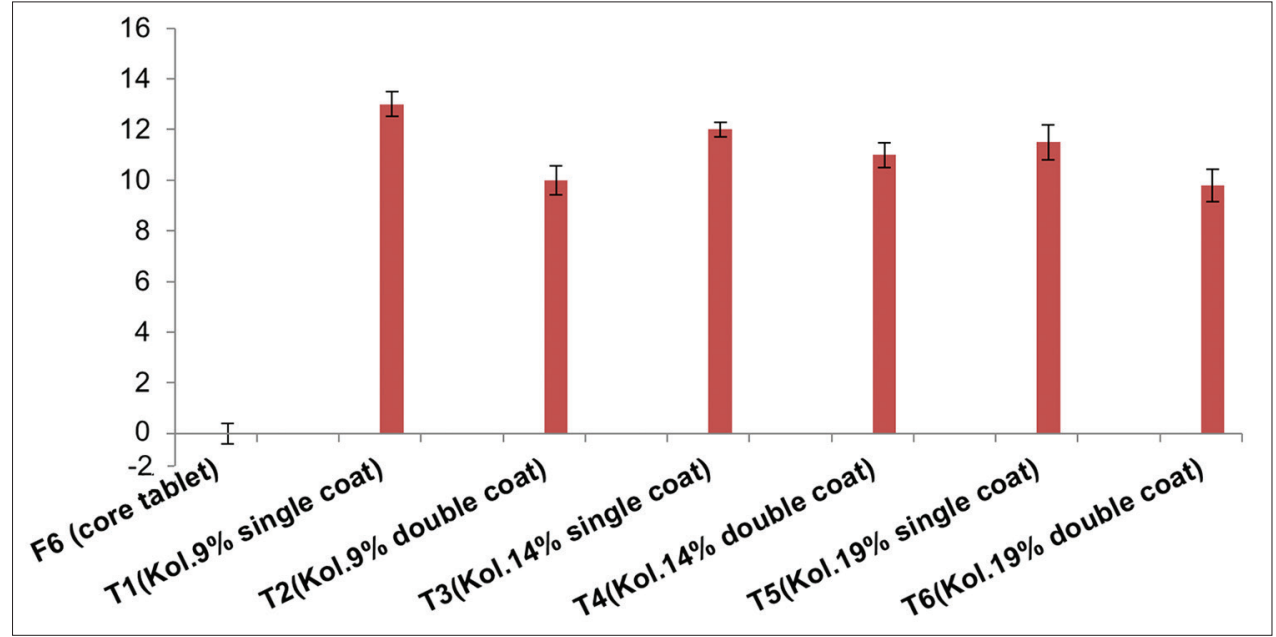

Fig. 7: The results of in vivo taste masking test for ranitidine hydrochloride buoyant core and oroslippery tablets, represented by mean \pm standard deviation $(n=3)$

significant effect on the in vivo slipperiness property, this may be due to the presence of xanthan gum in the coat which considers as slipperiness inducing agent to facilitate the swallowing process.
In addition, increasing the concentration of Kollicoat cause a nonsignificant increase $(p>0.05)$ in the degree of slipperiness, while the results of a double coating showed enhancement of the slipperiness, 
these observations might be attributed to increase the viscosity of the coating formula up on increasing the polymer concentration [27].

The results of in vivo taste masking for RHCl OSTs formulas T1-T6 and core tablet F6, (Fig. 7) revealed that a significant increase in taste masking in coated tablets (T1-T6) than the non-coated core tablet, because coating the tablet created a physical barrier between the drug and taste buds, In addition, the use of mannitol and peppermint oil resulted in a fine sweet taste, sense of coolness and freshness within the mouth $[29,30]$. Furthermore, the results showed a significant increase $(\mathrm{p}<0.05)$ in taste masking at the higher concentration of Kollicoat IR represented in T5 (19\% Kollicoat) comparing to T1 with (9\% Kollicoat) and $\mathrm{T} 3$ with (14\% Kollicoat), in addition the results showed that double coating which represented in T2, T4, and T6 formulas, have a significant improvement $(\mathrm{P}<0.05)$ in the in vivo taste masking effect comparing to monolayer coating in $\mathrm{T} 1, \mathrm{~T} 3$, and $\mathrm{T} 5$, respectively, these results might be due to the greater viscosity of the coating dispersion that observed by the higher Kollicoat concentrations in T6 which increased the hydrodynamic drag of the coating dispersion that finally gave a higher coat thickness [3]

\section{CONCLUSION}

Intragastric buoyant tablet of $\mathrm{RHCl}$ which coated with slippery coat can be successfully prepared and optimized, this type of tablet dosage form overcomes swallowing obstacles for certain population who experienced difficulty of swallowing, provide a good taste masking and meanwhile release the drug continuously in the stomach enhancing drug absorption and bioavailability. The results of in vitro evaluation to study the effect of coating types and the level of coating on $\mathrm{RHCl}$ buoyant core tablet on the release profile, FLT and in vivo slipperiness and taste masking test concluded that $\mathrm{T} 4$ has the optimum results, a promising release rate, an instant floating, an accepted slipperiness and taste masking effect. The results of RHCl buoyant OST formulations provide a positive impact for such a newly developed approach to tablet dosage form.

\section{ACKNOWLEDGMENT}

The authors would like to thank University of Mustansiriyah (www. uomustansiriyh.edu.iq) Baghdad, Iraq, for its support in the present work.

\section{REFERENCES}

1. Dineshmohan S, Vanitha K, Ramesh A, Srikanth G, Akila S. Formulation and evaluation of salbutamol sulphate fast dissolving tablet. Int J Pharm Biosci 2010;1:105-8.

2. Pandey VP, Ruby JJ. Orodispersible tablets-a review. World J Pharm Pharm Sci 2014;3:129-35.

3. Maraie NK, Alhamadany AT, Mahdi ZH. Application of the new oroslippery technology in the preparation of enteric slippery coated tablet of naproxen. Int J Pharm Pharm Sci 2017;9:198-204.

4. Sweetman SS. Martindale: The Complete Drug Reference. $36^{\text {th }}$ ed. London: Pharmaceutical Press; 2009. p. 381

5. Emara LA, Abdou AR, El-asmawy AA, Mursi NM. Preparation and evaluation of metronidazole sustained release floating tablets. Int $\mathrm{J}$ Pharm Pharm Sci 2014;6:198-204.

6. Albadry AA, Ali WK, Alsaady FA. Formulation and evaluation of prochlorperazine maleate sustained release floating tablet. Int J Pharm Pharm Sci 2016;9:89-98.

7. Singh S, Prajapati K, Pathak AK, Mishra A. Formulation and evaluation of floating tablet of captopril. Int J Pharmtech Res 2011;3:333-41.

8. Gulum S, Koksel F, Serpil S, Arzu B, Venkatesh M. Effect of xanthan and guar gums on quality and staling of gluten free cakes baked in microwave-infra red combination oven. Int $\mathrm{J}$ Food Sci Technol 2010;45:87-93.

9. Jaiswal H. Oral strip technology: A review. Indian J Pharm Biol Res 2014;2:130-43.

10. Mahdi ZH, Maraie NK. New easily swallowed tablets with slippery coating for the antihypertensive drug valsartan. UK J Pharm Biosci 2015;3:9-19.

11. McCabe TT, Stagner RA, Sutton JE. Inventors; Burroughs Wellcome Co., Research Triangle Park, N.C. Flavored Film-Coated Tablet. United States Patent US 005098715A; 1992

12. Yousif NZ, Mahmood SZ, Salman ZD. Solubility enhancement, formulation and evaluation of furosemide stomach specific mucoadhesive tablet. Sci Rev Res 2016;40:258-65.

13. Kalia A, Khurna S, Bedi N. Formulation and evaluation of mouth dissolving tablets of oxycarbazepine. Int $\mathrm{J}$ Pharm Pharm Sci 2009;1:12-23.

14. Ramesh KA, Shabaraya AR, Mohd A, Kamath KK. Formulation and evaluation of pulsatile drug delivery system containing indomethacin using natural polymers. Int Res J Pharm 2013;4:111-4.

15. Ingale RD, Thakare VM, Tekade BW, Patil VR. Development and evaluation of rantidine hydrochloride floating tablet. Int J Pharm Sci Res 2014;5:269-74.

16. Natarajan R, Kaveri N, Rajndran NN. Formulation and evaluation of aceclofenac gastro retentive retentive drug delivery system. Res J Pharm Biol Chem Sci 2011;2:765-71.

17. Kumar PD, Rathnam G, Prakash CR, Saravanan G, Karthick V, Selvam TP. Formulation and characterization of bilayer floating tablets of ranitidine. Rasayan J Chem 2010;3:368-74.

18. Mishra AN, Rana A. UV spectrophotometric determination of ranitidine hydrochlorided in pure and pharmaceutical formulation. J Chem Sci 2009;7:2208-10

19. Hsia R, Misra T, Saranteas K, Bonasia P Jr, Huang CG. Inventors; Sunovion Pharmaceuticals Inc. Coated Tablets of 6-(5-Chloro-2Pyridyl)-5-[(4-Methyl-1-Piperazinyl) carbonyloXy]-7-Oxo-6,7Dihydro-5hpyrrolo[3,4-b]Pyrazine and Methods for Measuring Effectiveness of Coating, Patent Candidate CA 2750059 A1; 2010.

20. Singh I, Saini V. Formulation and optimization of floating matrix tablets of clarithromycin using simplex lattice design. Pak J Pharm Sci 2016;29:511-9.

21. Srilakshmi P, Koushik KN, Raju SD, Rao RN, Prasanna LJ, Deepthi B. Formulation and evaluation of gastro retentive floating tablets of an antipsychotic drug. Am J Pharmtech Res 2014;4:470-6.

22. Rahman M, Roy S, Das SC, Jha MK, Begum T, Ahsan Q, et al. Evaluation of various grades of hydroxypropyl methylcellulose matrix systems as oral sustained release drug delivery systems. J Pharm Sci Res 2011;3:930-8.

23. Nicole K, Owen IC. Swelling and erosion properties of hydroxypropylmethylcellulose (hypromellose) matrices-influence of agitation rate and dissolution medium composition. Int J Pharm 2004;279:141-52.

24. Maraie NK, Mohsen M, Neama M, Zuwar N. Few factors affecting the buoyancy and release of theophylline anhydrous from hydrodynamically balanced delivery system. Indian J Sci Technol 2011;6:85-94.

25. Soniya C, Manojkumar P, Gorakhnath H, Audmbar M, Santosh J. Formulation and evaluation of floating tablets of nizatidine. Int J Res Ayurveda Pharm 2015;6:290-8

26. Patel D, Shivakumar S. Formulation and evaluation of floating capsules of $3^{\text {rd }}$ generation cephalosporin. Int J Pharmtech Res 2012;4:986-93.

27. Siepmann J, Seipmann F, Paeratakul O. Process formulation and factors affecting drug release from pellets coated with ethyl cellulose pseudolatex aquacoat. In: Felton LA, McGinity JW, editors. Aqueous Polymeric Coatings for Pharmaceutical Dosage Forms. $3^{\text {rd }}$ ed. USA: CBC Press, Taylor and Francis Group Publishing; 2008. p. 203-36.

28. Ishak RA. Buoyancy-generating agents for stomach-specific drug delivery: An overview with special emphasis on floating behavior. J Pharm Pharm Sci 2015;18:77-100.

29. Srivastava A. Recent technologies for the tast masking of bitter drugs. Int J Pharm Pharm Res 2012;3:578-86.

30. Balakrishnan A. Therapeutic uses of peppermint-a review. J Pharm Sci Res 2015;7:474-6. 